\title{
Short communication: Effect of timing of induction of ovulation relative to timed artificial insemination using sexed semen on pregnancy outcomes in primiparous Holstein cows
}

\author{
M. R. Lauber, ${ }^{1} \odot$ B. McMullen, ${ }^{2} \odot$ J. J. Parrish, ${ }^{3}{ }^{\oplus}$ and P. M. Fricke ${ }^{1 *} \oplus$ \\ ${ }^{1}$ Department of Dairy Science, University of Wisconsin-Madison, Madison 53706 \\ ${ }^{2}$ Bridgewater Dairy Group, Montpelier, OH 43543 \\ ${ }^{3}$ Department of Animal Sciences, University of Wisconsin-Madison, Madison 53706
}

\begin{abstract}
Our objective was to determine the effect of increasing the interval from induction of ovulation to timed artificial insemination (TAI) on fertility by decreasing the interval from TAI to ovulation using sexed semen within a synchronized breeding program. Our hypothesis was that induction of ovulation earlier relative to TAI would increase pregnancies per artificial insemination (P/AI). Primiparous Holstein cows from 3 commercial dairy farms in the United States were submitted to a Double-Ovsynch protocol for first service as follows: Pre-Ovsynch (GnRH; 7 d, $\mathrm{PGF}_{2 \alpha} ; 3$ d, GnRH), followed $7 \mathrm{~d}$ later by Breeding-Ovsynch [GnRH (G1); $7 \mathrm{~d}, \mathrm{PGF}_{2 \alpha} ; 24 \mathrm{~h}, \mathrm{PGF}_{2 \alpha}$ ], followed by the last $\mathrm{GnRH}$ treatment (G2), which varied between treatments, and TAI. To vary the interval between G2 and TAI, cows were randomized to 2 treatments to receive G2 either 16 $(\mathrm{G} 2-16 ; \mathrm{n}=373)$ or $24(\mathrm{G} 2-24 ; \mathrm{n}=357) \mathrm{h}$ before TAI, which was fixed at $48 \mathrm{~h}$ after the second $\mathrm{PGF}_{2 \alpha}$ treatment of the Breeding-Ovsynch portion of the protocol. All cows were inseminated with sexed semen, and each herd used sires of their choosing, which were randomly allocated between treatments. Pregnancy diagnosis was conducted by herd veterinarians using transrectal ultrasonography. In disagreement with our hypothesis, G2-24 cows had fewer P/AI than G2-16 cows at 34 $\pm 3 \mathrm{~d}(44$ vs. $50 \%)$ and $80 \pm 17 \mathrm{~d}(41$ vs. $48 \%)$ after TAI. Pregnancy loss ( 5 vs. $6 \%$ ) and fetal sex ratio (92:8 vs. 90:10, female:male) did not differ between treatments for G2-16 and G2-24 cows, respectively. Thus, we reject our hypothesis and conclude that induction of ovulation earlier relative to TAI with sexed semen for first service after a Double-Ovsynch protocol decreased $\mathrm{P} / \mathrm{AI}$ in primiparous Holstein cows.
\end{abstract}

Received May 4, 2020.

Accepted July 6, 2020.

*Corresponding author: pmfricke@wisc.edu
Key words: sexed semen, dairy cow, timing of artificial insemination

\section{Short Communication}

Sexed semen allows for strategic production of replacement heifers from genetically elite females, thereby accelerating genetic progress within a dairy herd. Use of sexed semen in Holstein females (nulliparous heifers and lactating cows) ranged from 1 to $12 \%$ from 2006 to 2016 , but rapidly increased to $15 \%$ by 2018 , and 20\% thus far in 2020 (R. Fourdraine, AgSource, Madison, WI, personal communication). A limitation of sexed semen, however, is that it yields conception rates 75 to $90 \%$ of conventional semen, thereby decreasing pregnancies per AI (P/AI) by approximately 5 to 10 percentage points (Seidel, 2014; Maicas et al., 2020; Perry et al., 2020). Modifications to the original sexing process over time have compensated for some of the cellular damage imposed by the sexing process (Faust et al., 2016a,b), but decreased fertility of sexed semen relative to conventional semen still persists. Initially, sexed semen was recommended for inseminating nulliparous dairy heifers after a detected estrus (Seidel et al., 1999) due to comparatively greater conception rates of sexed semen in heifers than in lactating dairy cows inseminated after a detected estrus (Norman et al., 2010).

Development of fertility programs for lactating dairy cows increased both service rate and $\mathrm{P} / \mathrm{AI}$ to timed artificial insemination (TAI) compared with a detected estrus (Santos et al., 2017). Use of sexed semen in lactating dairy cows, particularly primiparous cows that have higher fertility and more advanced genetics than multiparous cows, is now increasing on dairy farms; however, fertility of lactating dairy cows inseminated using sexed semen remains less than that using conventional semen (Karakaya-Bilen et al., 2019). Delayed insemination with sexed semen relative to the onset of increased physical activity associated with estrus 
increased the $\mathrm{P} / \mathrm{AI}$ of Jersey cows (Bombardelli et al., 2016; Nebel 2018). In contrast, timing of AI using sexed semen has not been evaluated within the context of a hormonal synchronization program in which timing of AI relative to induction of ovulation is precisely controlled. Thus, our objective was to determine the effect of altering timing of induction of ovulation relative to TAI with sexed semen after a Double-Ovsynch protocol in primiparous Holstein cows. Our hypothesis was that earlier induction of ovulation relative to TAI within a Double-Ovsynch protocol (i.e., inseminating closer to the time of ovulation) would increase $\mathrm{P} / \mathrm{AI}$.

This field study was conducted in collaboration with 3 commercial dairy farms in the United States located in Nebraska, Ohio, and Wisconsin. Farm A was milking approximately 6,650 cows with a 305-d mature-equivalent milk yield (ME305) of 11,318 $\mathrm{kg}$ and enrolled cows into the experiment from December 2018 to June 2019; farm B was milking approximately 1,800 cows with a ME305 of 12,970 $\mathrm{kg}$ and enrolled cows into the experiment from November 2018 to March 2019; farm $\mathrm{C}$ was milking approximately 2,260 cows with a ME305 of $14,060 \mathrm{~kg}$ and enrolled cows into the experiment from August 2019 to January 2020.

Primiparous Holstein cows $(\mathrm{n}=730)$ were submitted to a Double-Ovsynch protocol for first TAI as reported by Souza et al. (2008) and modified by Brusveen et al. (2009). Briefly, cows received the first GnRH treatment of the Pre-Ovsynch portion of the Double-Ovsynch protocol, followed by treatment with $\mathrm{PGF}_{2 \alpha} 7 \mathrm{~d}$ later, and treatment with GnRH 3 d later. Cows began the Breeding-Ovsynch portion of the Double-Ovsynch protocol $7 \mathrm{~d}$ later with treatment of $\mathrm{GnRH}$, followed by 2 $\mathrm{PGF}_{2 \alpha}$ treatments 7 and $8 \mathrm{~d}$ later. To vary the interval between the last GnRH treatment (G2) and TAI, cows selected for mating with sexed semen were randomized at G2 by odd versus even ear-tag number to 2 treatments to receive $\mathrm{G} 2$ of the Breeding-Ovsynch portion of the protocol. Cows were either assigned 16 h (G2-16; $\mathrm{n}=373)$ or $24 \mathrm{~h}(\mathbf{G 2}-\mathbf{2 4} ; \mathrm{n}=357)$ before TAI, which was fixed at $48 \mathrm{~h}$ after the second $\mathrm{PGF}_{2 \alpha}$ treatment of the Breeding-Ovsynch portion of the protocol (Figure 1). To vary the interval from induction of ovulation to TAI, G2-16 cows received G2 in the evening the day before TAI, whereas G2-24 cows received G2 in the morning the day before TAI. The TAI occurred in the morning the day after G2 for all cows in both treatments (Figure 1). Timing of G2 was altered rather than TAI to accommodate for farm labor efficiency and the infeasibility for AI technicians to inseminate cows twice daily. Based on an established time of ovulation between 24 to $32 \mathrm{~h}$ after G2 (Pursley et al., 1995), TAI for G2-16 cows occurred approximately 8 to $16 \mathrm{~h}$ before ovulation, whereas TAI for G2-24 cows occurred approximately 0 to $8 \mathrm{~h}$ before ovulation. The voluntary waiting period was $79 \pm 3$ DIM (mean \pm SEM; $78 \pm$ 2 for farm A, $84 \pm 2$ for farm B, and $78 \pm 2$ for farm C). The 3 farms used $\mathrm{GnRH}$ and $\mathrm{PGF}_{2 \alpha}$ products of their choosing in combinations within each manufacturer: Factrel $(100 \mu \mathrm{g}$ i.m. of gonadorelin hydrochloride; Zoetis, Madison, NJ) and Fertagyl (86 $\mu \mathrm{g}$ i.m. of gonadorelin; Merck Animal Health, Kenilworth, NJ), and Lutalyse (25 mg i.m. of dinoprost tromethamine; Zoetis) and Estrumate (526 $\mu \mathrm{g}$ i.m. of cloprostenol sodium; Merck Animal Health).

Experienced AI technicians inseminated cows with sexed semen (ABS Sexcel Sexed Genetics, ABS Global, DeForest, WI) once weekly in the morning on each farm throughout the experiment. Sexed semen was commercially processed using a commercialized micro-

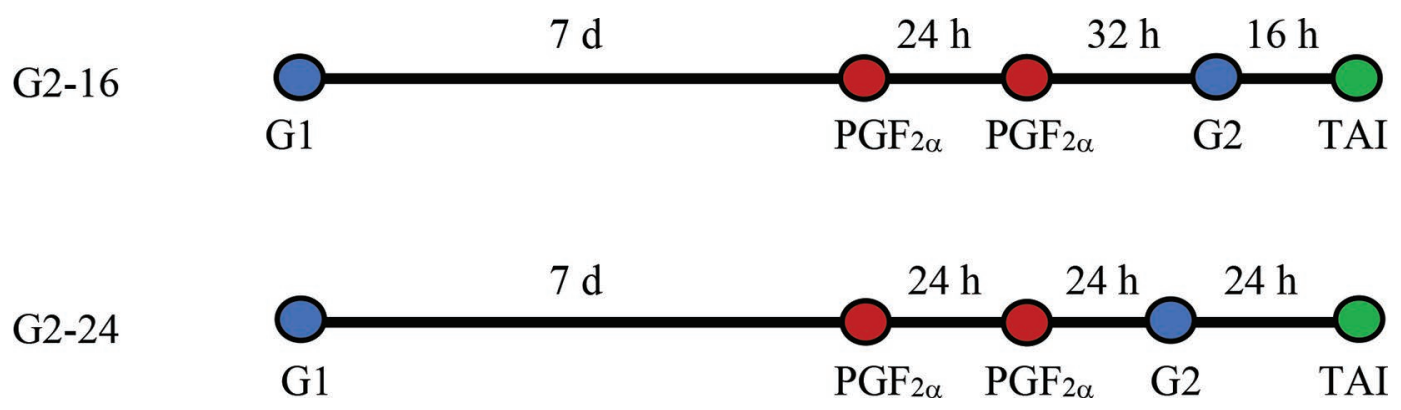

Figure 1. Schematic diagram of variations in the Breeding-Ovsynch portion of the Double-Ovsynch protocols to alter timing of the last GnRH treatment relative to TAI. Primiparous Holstein cows were submitted to a Double-Ovsynch protocol for first service as follows: PreOvsynch (GnRH; 7 d, $\mathrm{PGF}_{2} ; 3 \mathrm{~d}, \mathrm{GnRH}$ ), followed 7 d later by Breeding-Ovsynch [GnRH (G1); 7 d, PGF $; 24$ h, PGF $; 32$ h], followed by the last GnRH treatment (G2), which was varied between treatments, and TAI. To vary the interval between G2 and TAI, cows were randomized to 2 treatments to receive G2 either $16(\mathrm{G} 2-16 ; \mathrm{n}=373)$ or $24 \mathrm{~h}(\mathrm{G} 2-24 ; \mathrm{n}=357)$ before TAI. The TAI was fixed for all cows at $48 \mathrm{~h}$ after the second $\mathrm{PGF}_{2 \alpha}$ treatment of the Breeding-Ovsynch portion of the protocol. $\mathrm{PGF}_{2 \alpha}=$ prostaglandin $\mathrm{F}_{2 \alpha}$; G1 $=$ first GnRH treatment of the Breeding-Ovsynch portion of the Double-Ovsynch protocol; G2 = second GnRH treatment of the Breeding-Ovsynch portion of the DoubleOvsynch protocol; TAI = timed artificial insemination. 
fluidics and laser-based cell destruction technology that has yielded acceptable conception rates in field studies (Faust et al., 2016a,b; Perry et al., 2020). It was packaged with approximately $2.1 \times 10^{6}$ sperm, $1.05 \times 10^{6}$ post-thaw, with $\sim 90 \%$ accuracy of X-bearing sperm. A total of 37 sires were used across the 3 collaborating herds. Sires were chosen by collaborating herds based on their respective genetic mating criteria and were evenly allocated between treatments within each herd.

Pregnancy status was diagnosed by herd veterinarians using transrectal ultrasonography $34 \pm 3 \mathrm{~d}$ after TAI. A positive pregnancy diagnosis was distinguished by the presence of a fetal heartbeat and a corpus luteum on the ovary ipsilateral to the uterine horn containing the fetus. Pregnancy reconfirmation was conducted $80 \pm 17$ $\mathrm{d}$ after TAI using transrectal ultrasonography, and fetal sex was diagnosed at $71 \pm 4 \mathrm{~d}$ after TAI on 2 of the 3 collaborating farms. Cows diagnosed pregnant and subsequently diagnosed not pregnant were considered to have undergone pregnancy loss. Pregnancy outcomes were recorded in a commercial dairy herd management software program (Dairy Comp 305, Valley Ag Software, Tulare, CA), and computer backup files were downloaded weekly and archived for subsequent data extraction and analysis.

This experiment used a complete randomized block design with farm included as a blocking factor. Based on an a priori power calculation (Thrusfield et al., 2001), inclusion of a minimum of 305 cows per treatment allowed for detection of a 10-percentage point difference in P/AI (40 to 50\%; 95\% CI; $80 \%$ power; 1 -sided test). All statistical analyses were performed using SAS computational software version 9.4 for Microsoft Windows (SAS Institute Inc., Cary, NC). Binary response data ( $\mathrm{P} / \mathrm{AI}$ and pregnancy loss) were analyzed by logistic regression using the GLIMMIX procedure of SAS. Treatment was considered a fixed effect and was forced to remain in the statistical models. Sire nested within farm was initially included as a random effect in the statistical models for $\mathrm{P} / \mathrm{AI}$ at $34 \pm 3 \mathrm{~d}, \mathrm{P} / \mathrm{AI}$ at 80 $\pm 17 \mathrm{~d}$, and pregnancy loss, but sire within farm was removed because of insignificant covariance $(P=0.13$, $P=0.20$, and $P=1.00$, respectively) which was analyzed using the ZeroG test of the GLIMMIX procedure of SAS. Thus, the final statistical model included only the fixed effect of treatment. Fetal sex ratio, which was assessed on 2 of the 3 collaborating farms, was analyzed using Fisher's exact test of SAS. A significant difference in the fixed effect was considered when $P \leq 0.05$, and a statistical tendency when $0.10 \leq P \geq 0.05$. Data are presented as proportions obtained using the PROC FREQ procedure of SAS.

Our objective was to determine the effect of increasing the interval from induction of ovulation to TAI in a Double-Ovsynch protocol using sexed semen in lactating primiparous Holstein cows. Our hypothesis was that earlier induction of ovulation relative to TAI in a Double-Ovsynch protocol (i.e., inseminating closer to presumed time of ovulation) with sexed semen would increase $\mathrm{P} / \mathrm{AI}$ in primiparous lactating Holstein cows synchronized for first service. Contrary to our hypothesis, G2-24 cows had fewer P/AI than G2-16 cows 34 \pm 3 (44 vs. $50 \% ; P=0.05$ ) and $80 \pm 17$ (41 vs. $48 \%$; $P=0.03) \mathrm{d}$ after TAI (Table 1 ). This disagrees with observational studies in which delayed insemination of Jersey cows with sexed semen relative to the onset of the increased physical activity associated with estrus (based on activity monitoring systems) increased $\mathrm{P} / \mathrm{AI}$ (Bombardelli et al., 2016; Nebel 2018). In a recent study, delaying TAI relative to synchronization of ovulation in Holstein heifers submitted to a 5-d CIDR-Synch protocol did not affect fertility (Chebel and Cunha, 2020). Timing of ovulation relative to the onset of physical activity is highly variable among lactating Holstein cows because high-producing cows exhibit a decreased expression of estrus, an increased interval from onset of estrus to ovulation, and a shorter duration of estrus (Valenza et al., 2012). Thus, the increase in P/AI with sexed semen observed by Bombardelli et al. (2016) and Nebel (2018) may also occur with conventional semen because cows were inseminated at a more optimal time relative to ovulation because of the longer interval from onset of estrus to ovulation.

The optimal interval from induction of ovulation to insemination is crucial to allow sufficient time for sperm transport and capacitation relative to ovulation. When timing of G2 relative to TAI was altered in the present experiment, timing of ovulation relative to G2 of approximately 24 to $32 \mathrm{~h}$ after GnRH treatment (Pursley et al., 1995), as well as oocyte lifespan of 6 to $12 \mathrm{~h}$ after ovulation, remained constant. By contrast, timing of sperm transport and capacitation relative to ovula-

Table 1. Effect of altering timing of induction of ovulation (G2) relative to timed artificial insemination (TAI) with sexed semen on pregnancies per artificial insemination $(\mathrm{P} / \mathrm{AI})$, pregnancy loss, and fetal sex in primiparous Holstein cows

\begin{tabular}{lccc}
\hline & \multicolumn{2}{c}{ Treatment $^{1}$} & \\
\cline { 2 - 3 } Item & G2-16 & G2-24 & P-value \\
\hline $\mathrm{P} /$ AI 34 $\pm 3 \mathrm{~d}, \%(\mathrm{n} / \mathrm{n})$ & $50(186 / 373)$ & $44(156 / 357)$ & 0.05 \\
$\mathrm{P} /$ AI $80 \pm 17 \mathrm{~d}, \%(\mathrm{n} / \mathrm{n})$ & $48(177 / 370)$ & $41(145 / 355)$ & 0.03 \\
Pregnancy loss, \% (n/n) & $5(9 / 184)$ & $6(9 / 154)$ & 0.70 \\
Female fetuses, $\%$ (n/n) & $92(116 / 126)$ & $90(90 / 100)$ & 0.64 \\
\hline
\end{tabular}

${ }^{1}$ Cows were submitted to a Double-Ovsynch protocol for first TAI with sexed semen and randomized to receive G2 16 h before TAI (G2-16) or $24 \mathrm{~h}$ before TAI (G2-24).

${ }^{2}$ Fetal sex was diagnosed by herd veterinarians $71 \pm 4 \mathrm{~d}$ after TAI using transrectal ultrasonography on 2 of the 3 collaborating farms. 
tion differed between treatments in the present study when timing of G2 was altered relative to TAI. Bovine sperm require 8 to $12 \mathrm{~h}$ for sustained transport to the isthmus section of the oviduct (Hunter and Wilmut, 1983). Thus, for G2-16 cows, sexed sperm would have 8 to $16 \mathrm{~h}$ for sustained transport to the isthmus; whereas for G2-24 cows, sexed sperm would only have 0 to $8 \mathrm{~h}$ for sustained transport to the isthmus. Further, bovine sperm require incubation with glycosaminoglycans in the oviduct for sperm to capacitate to then undergo an acrosome reaction and fertilize an oocyte. In vitro capacitation of conventional bovine sperm requires approximately $4 \mathrm{~h}$ of incubation with heparin (Parrish et al., 1988). Cryopreserved sexed sperm exhibit membrane changes resembling a precapacitated state; however, it is not clear if membrane changes represent true achievement of capacitation or an accelerated in vitro capacitation rate (Mocé et al., 2006; Bucci et al., 2012). Thus, membrane damage of sexed sperm due to the sexing process may not accelerate capacitation; rather, the membrane-damaged sperm may be rapidly transported to the peritoneal cavity where they cannot fertilize the oocyte. Only a maximum of $8 \mathrm{~h}$ was available for viable sperm in G2-24 cows for sustained transport and capacitation, which was likely insufficient, and thereby resulted in fewer P/AI. Pursley et al. (1998) reported that the most $\mathrm{P} / \mathrm{AI}$ when TAI occurred $16 \mathrm{~h}$ after $\mathrm{G} 2$, and observed a 4-percentage point decrease in $\mathrm{P} / \mathrm{AI}$ when TAI occurred either 8 or $24 \mathrm{~h}$ after G2 in the first study assessing timing of AI with conventional semen relative to a synchronized ovulation after an Ovsynch protocol. In agreement with that study, we observed a 6 -percentage point decrease in $\mathrm{P} / \mathrm{AI} 34 \pm 3 \mathrm{~d}$ after TAI with sexed semen when the interval from G2 to TAI was increased from 16 to $24 \mathrm{~h}$.

To test our hypothesis under field conditions, we altered timing of G2 rather than TAI within the Double-Ovsynch protocols to accommodate farm labor and because AI technicians could not visit farms twice daily. Based on our experimental design, however, induction of ovulation earlier relative to TAI likely resulted in slight alterations of progesterone (P4) and estradiol concentrations during the protocol in addition to altering timing of AI relative to ovulation. Cows with $\mathrm{P} 4$ concentrations $\geq 0.4 \mathrm{ng} / \mathrm{mL}$ at $\mathrm{G} 2$ had fewer $\mathrm{P} / \mathrm{AI}$ than cows with $<0.4 \mathrm{ng} / \mathrm{mL}$ (Carvalho et al., 2018). In the present study, G2-24 cows had 8 h less to complete luteolysis, thereby limiting time for P4 concentrations to decrease completely to allow for high fertility. Further, by administrating G2 earlier relative to TAI, G2-24 cows likely ovulated a smaller follicle than G2-16 cows because follicles had 8 fewer hours to develop during the synchronized follicular wave. Pre- ovulatory dominant follicles grow approximately 2 to $3 \mathrm{~mm}$ per day during a follicular wave (Sartori et al., 2001). Thus, the difference in diameter of the ovulatory follicle between treatments in the present study would be approximately 0.7 to $1 \mathrm{~mm}$. Peters and Pursley (2003) reported decreased ovulatory follicle size and P/ AI when the interval from $\mathrm{PGF}_{2 \alpha}$ to $\mathrm{G} 2$ was decreased from 36 to $0 \mathrm{~h}$, and cows had the fewest P/AI when $\mathrm{G} 2$ was administered concurrently with $\mathrm{PGF}_{2 \alpha}$. In cows manipulated to ovulate follicles that averaged a difference of $3 \mathrm{~mm}$ in diameter, cows that ovulated smaller follicles produced smaller corpus luteum, resulting in decreased serum P4 after TAI and fewer P/AI (Vasconcelos et al., 2001). By contrast, temporarily decreasing P4 after TAI in lactating dairy cows decreased embryonic growth, but did not decrease P/AI or pregnancy loss (Carvalho et al., 2017). Crossbred Holstein cows in Brazil submitted to a synchronized breeding protocol using estradiol and progesterone had fewer P/AI than cows inseminated based on a synchronized estrus when using sexed semen (Sá Filho et al., 2013). Thus, type of synchronized breeding protocol and manipulation of hormone levels at key points during the protocol affect pregnancy outcomes when using sexed semen in conjunction with TAI. Taken together, differences in follicle size, P4, and timing of induction of ovulation relative to TAI were confounded with timing of AI relative to synchronization of ovulation based on the experimental design of the present study. Nonetheless, from a practical perspective, the protocol modification we tested in the present study in conjunction with sexed semen in primiparous Holstein cows decreased fertility compared with a standard Double-Ovsynch protocol.

Pregnancy loss was $6 \%$ and 5\% for G2-24 and G2-16 cows, respectively, and did not differ $(P=0.70)$ between treatments (Table 1 ). The proportion of female fetuses did not differ between treatments $(P=$ $0.64)$ and was similar to that reported in other studies with sexed semen (DeJarnette et al., 2009), with approximately $90 \%$ of fetuses diagnosed female using transrectal ultrasonography at the pregnancy recheck (Table 1). Pursley et al. (1998) reported that fetal sex ratio was skewed toward females when the timing of insemination with conventional semen was 0 or $32 \mathrm{~h}$ relative to G2 of an Ovsynch protocol; however, more total females were produced when TAI occurred $16 \mathrm{~h}$ after G2 when P/AI was greatest. The proportion of female fetuses observed in the present study may not have differed between treatments because cows were inseminated with a highly skewed population of $90 \%$ X-bearing sperm cells.

In conclusion, and in disagreement with our hypothesis, induction of ovulation earlier relative to TAI after 
a Double-Ovsynch protocol decreased P/AI in primiparous Holstein cows, whereas pregnancy loss and proportion of female fetuses did not differ between treatments. Delaying insemination based on detection of estrus may increase P/AI because of the longer interval from the onset of estrus to ovulation and shorter duration of estrus in high-producing lactating dairy cows, but not in cows submitted to TAI after synchronization of ovulation in which timing of AI relative to ovulation is precisely controlled. Based on our data, inseminating cows with sexed semen $16 \mathrm{~h}$ after G2 yielded more $\mathrm{P} /$ AI than when cows were inseminated $24 \mathrm{~h}$ after G2. The decreased $\mathrm{P} / \mathrm{AI}$ observed by increasing the interval from induction of ovulation relative to TAI may be attributable to decreased time for sperm transport and capacitation as well as differences in the hormonal milieu at critical time points near the end of the synchronization protocol.

\section{ACKNOWLEDGMENTS}

We thank the Bridgewater Dairy Group (Montiplier, $\mathrm{OH})$, Double P Dairy (Marathon, WI), and Rams Horn Dairy (McCook, NE) for use of their cows and facilities. We thank ABS Global (Deforest, WI) for technical services and Valley Ag Software (Tulare, CA) for DairyComp 305 Software. This work was supported by the USDA National Institute of Food and Agriculture (Washington, DC) Hatch project 1019532 and ABS Global to P.M. Fricke. The authors have not stated any conflicts of interest.

\section{REFERENCES}

Bombardelli, G. D., H. F. Soares, and R. C. Chebel. 2016. Time of insemination relative to reaching activity threshold is associated with pregnancy risk when using sex-sorted semen for lactating Jersey cows. Theriogenology 85:533-539. https://doi.org/10.1016/ j.theriogenology.2015.09.042.

Brusveen, D. J., A. H. Souza, and M. C. Wiltbank. 2009. Effects of additional prostaglandin F $2 \alpha$ and estradiol-17 $\beta$ during Ovsynch in lactating dairy cows. J. Dairy Sci. 92:1412-1422. https://doi.org/ 10.3168/jds.2008-1289.

Bucci, D., G. Galeati, C. Tamanini, C. Vallorani, J. E. Rodriguez-Gil, and M. Spinaci. 2012. Effect of sex sorting on CTC staining, actin cytoskeleton and tyrosine phosphorylation in bull and boar spermatozoa. Theriogenology 77:1206-1216. https://doi.org/10.1016/j .theriogenology.2011.10.028.

Carvalho, P. D., C. C. Consentini, S. R. Weaver, R. V. Barleta, L. L. Hernandez, and P. M. Fricke. 2017. Temporarily decreasing progesterone after timed artificial insemination decreased expression of interferon-tau stimulated gene 15 (ISG15) in blood leukocytes, serum pregnancy-specific protein $\mathrm{B}$ concentrations, and embryo size in lactating Holstein cows. J. Dairy Sci. 100:3233-3242. https: //doi.org/10.3168/jds.2016-11996.

Carvalho, P. D., V. G. Santos, J. O. Giordano, M. C. Wiltbank, and P. M. Fricke. 2018. Development of fertility programs to achieve high 21-day pregnancy rates in high-producing dairy cows. Theriogenology 114:165-172. https://doi.org/10.1016/j.theriogenology 2018.03.037.
Chebel, R. C., and T. Cunha. 2020. Optimization of timing of insemination of dairy heifers inseminated with sex-sorted semen. J. Dairy Sci. 103:5591-5603. https://doi.org/10.3168/jds.2019-17870.

DeJarnette, J. M., R. L. Nebel, and C. E. Marshall. 2009. Evaluating the success of sex-sorted semen in US dairy herds from on farm records. Theriogenology 71:49-58. https://doi.org/10.1016/j .theriogenology.2008.09.042.

Faust, M. A., J. Betthauser, S. Crego, and A. Storch. 2016a. Fertility and sex of calf results from a new commercial scale technology platform for producing sexed sperm. J. Dairy Sci. 99(Suppl. 1):544.

Faust, M. A., J. Betthauser, A. Storch, and S. Crego. 2016b. Effects for fertility of processing steps of a new technology platform for producing sexed sperm. J. Dairy Sci. 99(Suppl. 1):544.

Hunter, R. H. F., and I. Wilmut. 1983. The rate of functional sperm transport into the oviducts of mated cows. Anim. Reprod. Sci. 5:167-173. https://doi.org/10.1016/0378-4320(83)90023-4.

Karakaya-Bilen, E., G. Yilmazbas-Mecitoglu, A. Keskin, B. Guner, E. Serim, J. E. P. Santos, and A. Gumen. 2019. Fertility of lactating dairy cows inseminated with sex-sorted or conventional semen after Ovsynch, Presynch-Ovsynch and Double-Ovsynch protocols. Reprod. Domest. Anim. 54:309-316. https://doi.org/10.1111/rda 13363.

Maicas, C., S. A. Holden, E. Drake, A. R. Cromie, P. Lonergan, and S. T. Butler. 2020. Fertility of frozen sex-sorted sperm at $4 \times 10^{6}$ sperm per dose in lactating dairy cows in seasonal-calving pasturebased herds. J. Dairy Sci. 103:929-939. https://doi.org/10.3168/ jds.2019-17131.

Mocé, E., J. K. Graham, and J. L. Schenk. 2006. Effect of sex-sorting on the ability of fresh and cryopreserved bull sperm to undergo an acrosome reaction. Theriogenology 66:929-936. https://doi.org/10 .1016/j.theriogenology.2006.01.063.

Nebel, R. 2018. Time of insemination relative to onset of activity threshold of cow manager is associated with pregnancy risk when using gender selected semen for Jersey cattle. Dairy and Vet. Sci. J. 5:1-3. https://doi.org/10.19080/JDVS.2018.05.555653.

Norman, H. D., J. L. Hutchison, and R. H. Miller. 2010. Use of sexed semen and its effect on conception rate, calf sex, dystocia, and stillbirth of Holsteins in the United States. J. Dairy Sci. 93:38803890. https://doi.org/10.3168/jds.2009-2781.

Parrish, J. J., J. Suskoparrish, M. A. Winer, and N. L. First. 1988. Capacitation of bovine sperm by heparin. Biol. Reprod. 38:11711180. https://doi.org/10.1095/biolreprod38.5.1171.

Perry, G. A., J. A. Walker, J. J. J. Rich, E. J. Northrop, S. D. Perkins, E. E. Beck, M. D. Sandbulte, and F. B. Mokry. 2020. Influence of Sexcel (gender ablation technology) gender-ablated semen in fixed-time artificial insemination of beef cows and heifers. Theriogenology 146:140-144. https://doi.org/10.1016/j.theriogenology .2019.11.030.

Peters, M. W., and J. R. Pursley. 2003. Timing of final GnRH of the Ovsynch protocol affects ovulatory follicle size, subsequent luteal function, and fertility in dairy cows. Theriogenology 60:1197-1204. https://doi.org/10.1016/S0093-691X(03)00120-1.

Pursley, J. R., M. O. Mee, and M. C. Wiltbank. 1995. Synchronization of ovulation in dairy cows using PGF(2-alpha) and GnRH. Theriogenology 44:915-923. https://doi.org/10.1016/0093 $-691 \mathrm{X}(95) 00279-\mathrm{H}$.

Pursley, J. R., R. W. Silcox, and M. C. Wiltbank. 1998. Effect of time of artificial insemination on pregnancy rates, calving rates, pregnancy loss, and gender ratio after synchronization of ovulation in lactating dairy cows. J. Dairy Sci. 81:2139-2144. https://doi.org/ 10.3168/jds.S0022-0302(98)75790-X

Sá Filho, M. F., M. F. Mendanha, R. V. Sala, F. J. Carvalho, L. H. C. Guimaraes, and P. S. Baruselli. 2013. Use of sex-sorted sperm in lactating dairy cows upon estrus detection or following timed artificial insemination. Anim. Reprod. Sci. 143:19-23. https://doi .org/10.1016/j.anireprosci.2013.10.014.

Santos, V. G., P. D. Carvalho, C. Maia, B. Carneiro, A. Valenza, and P. M. Fricke. 2017. Fertility of lactating Holstein cows submitted to a Double-Ovsynch protocol and timed artificial insemination versus artificial insemination after synchronization of estrus at a 
similar day in milk range. J. Dairy Sci. 100:8507-8517. https://doi .org/10.3168/jds.2017-13210.

Sartori, R., P. M. Fricke, J. C. P. Ferreira, O. J. Ginther, and M. C. Wiltbank. 2001. Follicular deviation and acquisition of ovulatory capacity in bovine follicles. Biol. Reprod. 65:1403-1409. https:// doi.org/10.1095/biolreprod65.5.1403.

Seidel, G. E. Jr. 2014. Update on sexed semen technology in cattle. Animal 8(s1):160-164. https://doi.org/10.1017/S1751731114000202.

Seidel, G. E. Jr., J. L. Schenk, L. A. Herickhoff, S. P. Doyle, Z. Brink, R. D. Green, and D. G. Cran. 1999. Insemination of heifers with sexed sperm. Theriogenology 52:1407-1420. https://doi.org/10 .1016/S0093-691X(99)00226-5.

Souza, A. H., H. Ayres, R. M. Ferreira, and M. C. Wiltbank. 2008. A new presynchronization system (Double-Ovsynch) increases fertility at first postpartum timed AI in lactating dairy cows. Theriogenology 70:208-215. https://doi.org/10.1016/j.theriogenology 2008.03.014

Thrusfield, M., C. Ortega, I. de Blas, J. P. Noordhuizen, and K. Frankena. 2001. WIN EPISCOPE 2.0: Improved epidemiological software for veterinary medicine. Vet. Rec. 148:567-572. https://doi .org/10.1136/vr.148.18.567.
Valenza, A., J. O. Giordano, G. Lopes Jr., L. Vincenti, M. C. Amundson, and P. M. Fricke. 2012. Assessment of an accelerometer system for detection of estrus and treatment with gonadotropin-releasing hormone at the time of insemination in lactating dairy cows. J. Dairy Sci. 95:7115-7127. https://doi.org/10.3168/jds.2012-5639.

Vasconcelos, J. L. M., R. Sartori, H. N. Oliveira, J. G. Guenther, and M. C. Wiltbank. 2001. Reduction in size of the ovulatory follicle reduces subsequent luteal size and pregnancy rate. Theriogenology 56:307-314. https://doi.org/10.1016/S0093-691X(01)00565-9.

\section{ORCIDS}

M. R. Lauber (๑) https://orcid.org/0000-0003-4123-3241

B. McMullen @ https://orcid.org/0000-0002-8611-3502

J. J. Parrish @ https://orcid.org/0000-0002-4085-556X

P. M. Fricke (i) https://orcid.org/0000-0002-1488-7672 